\title{
Background Feelings of Belonging and Psychological Trauma
}

\author{
Lillian Wilde \\ Department of Philosophy, University of York, York, UK
}

\section{Keywords}

Alienation · Belonging · Communal experience .

Gerda Walther · Post-traumatic stress disorder - Trauma •

We-intentionality

\begin{abstract}
Reports of not feeling understood are frequent in testimonies of psychological trauma. I argue that these feelings are not a matter of a cognitive failure but rather an expression of the absence of a more pervasive background feeling of belonging. Contemporary accounts of we-intentionality promise but ultimately fall short in explaining this sense of belonging. Gerda Walther offers an alternative account of communal experiences. Her notion of "habitual unification" can explain the background feelings of belonging that are woven through the individual's everyday experience of being in a shared world. Having unified with another person, the world feels different. It is now experienced in light of a "we." This is not only the case in actual, singular person-toperson encounters. Unification with others becomes habitual: it retreats into the background of the individual's awareness, colouring their experience of the world. Thus sedimented, it forms a background sense of belonging to a shared world. Unification is enabled by experiencing others as being similar in a significant way, such as having the same experiences, values, or basic attitude: in Walther's
\end{abstract}

karger@karger.com

(c) 2021 S. Karger AG, Basel

www.karger.com/psp

Karger! words, as being a "human, who also...." This, I shall argue, is impacted through traumatizing experiences. Trauma survivors struggle to experience others as "humans, who also...," resulting in a failure of unification and thus impeding feelings of belonging. Trauma testimonies also suggest that actively seeking out recognition of similarities and shared aspects of experience may once again enable experiencing others as "humans, who also...," thus enabling unification and re-establishing a sense of belonging.

(c) 2021 S. Karger AG, Basel

\section{Introduction}

Alienation, the feeling of being a stranger and not being understood by those one is surrounded by, is an experience that is frequently reported in the trauma literature (e.g., $[1,2])$. It is not clear, however, what the feeling of being understood or its absence amount to. In the following, I will argue that feeling understood is not merely a cognitive achievement but rather an expression of the absence of a more pervasive background feeling of belonging, of being one of us. Accounts of weintentionality, such as joint agency, shared emotions, or plural subjecthood, promise but ultimately fall short in explaining this sense of belonging. What is needed is an explanation of the pre-reflective sense of belonging that 
constitutes the feeling of being understood. Phenomenologist Gerda Walther [3] offers an account of unification that promises to fill this lacuna. Other parts of her philosophy have enjoyed increased interest in the past years; her account of unification, however, has remained underexplored. I think that it can be informative and ultimately add to our understanding of the feelings of alienation encountered in reports of trauma survivors. It draws attention to 3 key aspects of feelings of belonging: their affective and their habitual nature, as well as their close link with how others are experienced, namely, in Walther's words, as being "humans, who also..." [3]. I interpret this concept - which Walther leaves intentionally open-ended through the use of the ellipsis - as experiencing others as being similar to oneself in a significant way, such as having the same experiences, values, or basic attitude. This, I shall argue, is impacted through traumatizing experiences: after experiencing the unimaginable, trauma survivors may struggle to experience others as "humans, who also...." This, in turn, implies a breakdown of unification. Where formerly the world was given as a meaningfully shared space, the traumatized individual no longer experiences themself as having the same basic attitude, values, or thought patterns as others. Unification and the sense of belonging it constitutes are impeded, and so is the feeling of being understood.

I will begin by exploring what background feelings of belonging amount to. I shall draw on recent phenomenological literature on communal experiences that promises to explain how feelings of being part of a group, collective, or "we" are constituted. While they go some way towards explaining feelings of belonging, they cannot account for the non-actual or background sense of belonging at stake in trauma. I will therefore continue by exploring Gerda Walther's work and develop a phenomenology of background feelings of belonging based on her account of unification as both affective and habitual. In the final section, I will illustrate this by applying it to the absence of background feelings of belonging in trauma. I will conclude with a brief exploration of the potential practical implications of these findings: trauma testimonies suggest that actively seeking out recognition of similarities and shared aspects of experience may once again facilitate experiencing others as "humans who also...," thus enabling connections with like-minded people and finding solace in community. Unification, once lost, is not lost forever, and the feeling of being understood can be re-established.

\section{Towards an Account of Background Feelings of Belonging}

The feeling of being understood can describe a range of experiences, from the feeling arising out of a successful exchange of propositions to a more pervasive and subtle sense of acceptance and connection. In the context of post-traumatic experiences, the notion of feeling understood that appears to be most relevant is, as I shall argue in the following, dependent upon or even identical to a feeling of belonging. "Belonging" is a multifaceted concept and can be applied in a variety of contexts: one can belong to a place, a club, a political party, a shared world at large (in Heidegger's [4] terminology: "Mitwelt"), and more (see e.g., [5-7]). This article focuses on the feeling of belonging to a group or a community: the feeling of being "one of us." The relevant sense of "belonging" here is both affective by nature and remains in the background of experience. It is affective in the sense that it does not involve a cognitive process of thinking about or positing oneself as belonging to another; it is a feeling of having a special kind of connection with the other. It is furthermore pre-reflective and, in this sense, remains in the background of experience, unless exceptional circumstances bring it to the fore. Only when it is disturbed, or the individual is otherwise prompted to reflect on their sense of belonging, does it become focal.

The active philosophical debate concerning communal experiences and we-intentionality seems to be a suitable candidate to explain what constitutes background feelings of belonging to a group or community or a sense of being "one of us." Accounts of joint agency, shared emotions, and plural subjecthood all go some way towards explaining how subjects come to experience themselves as feeling or acting together with one another, as being part of a collective, or a "we" (e.g., [8-12]). Many of the accounts, however, tend to focus on episodic interactions and rely on a notion of background feelings of belonging or togetherness to explain actualized we-experiences such as acting together or sharing an emotion, rather than offering an explanation of how the feeling of belonging is constituted in the first place. In the following, I shall briefly outline 3 of the core debates surrounding collective intentionality, and show why they do not, in fact, succeed in explaining the background nature of feelings of belonging. I will then proceed to elaborate on Gerda Walther's account of habitual unification and demonstrate that it is a more suitable candidate to do so. 


\section{Joint Agency}

Joint agency (also "we-agency," or "plural agency") accounts for feelings of togetherness by explaining how subjects come to feel like being a plural agent, that is, acting together as a group. Explanations vary: Pacherie, for example, suggests that a sense of we-agency is rooted in coordination, joint predictions, and a common goal [8]; Helm takes communal cares marked by patterns of shared emotions, desires, and evaluative judgements to be central to the formation of a plural agent [9]. For both authors, subjects need to be engaged in the same activity or activities with a common goal, mutually aware of one another, and of one another's actions and intentions. The affective sense of we-ness, or what it is like to act together, remains largely unaddressed [13]. A notable exception are cases of "pure we-agency" [8], like dancing or military drills, in which individuals are said to feel like they are one [8]. This example, however, highlights that the phenomenon to be explained here is not a pervasive background feeling of belonging but rather an experience of phenomenological fusion that, at its most successful, obliterates the experiential distinction between subjects. It is furthermore tied to a specific episodic interaction: when the action ends, so does the feeling of togetherness. Thus, accounts of joint agency cannot explain the more pervasive sense of belonging that is not tethered to any specific (shared) action.

\section{Shared Emotions}

Another way of explaining feelings of togetherness is by appealing to emotional sharing. It is generally accepted that in order to share something, the plurality of subjects needs to be preserved: I cannot share something with myself. Sharing requires reciprocal other-awareness and thus presupposes a plurality of subjects, as for example León et al. [12] and Zahavi [14] argue. Several contemporary scholars of we-intentionality have engaged with the question of what it means to share an experience or, more specifically, an emotion. The debate on shared emotions has focused predominantly on the question of whether or not one token emotion can be had by multiple subjects and what this sharing amounts to $[10,15]$. Scheler's famous passage on the experience of parents grieving their child is often referred to in order to illustrate that the 2 parents share the feeling of grief for their child. They are grieving together [16]. Whether we are faced here with one token emotion had by both parents, or whether the parents fuse to form a plural subject is debated. The latter suggestion is usually countered with the requirement set out earlier, that is, preserving the plurality of subjects.
León et al. [12] furthermore suggest that, in addition to reciprocal other-awareness, an identification with the other leading to an integration of the respective emotional experiences is required for a properly shared emotion. In their words, "to feel an emotion not simply as one's own but as ours, requires that one identifies with the other(s) in order to experience oneself as one of us." The authors point out that the shared emotion can be experienced differently by each of the subjects involved; it is sufficient for the subject's complementary emotions to converge in an overarching feeling for it to be a shared experience. The authors explain "emotional convergence" to be "an overarching integration of complementary emotional experiences" [12]. Without going into further detail, let us just note that, importantly, the shared feeling only exists in relation to the other subject's emotion and therefore does not breach the plurality requirement. Thus, for a properly shared emotion, the right balance of self-other difference and identification with the other through the emphasis of similarities needs to be struck. How 2 individuals come to identify with one another and integrate their experiences remains, however, unclear. Furthermore, even if we can account for the shared emotion episode, this does not serve as an argument for a pervasive sense of belonging to a shared world and the feeling of being understood it constitutes. The moment the shared emotion is no longer experienced, the communal experience ceases too.

\section{Plural Subjecthood}

Schmid's account of plural subjecthood aims to go a step further than accounts of plural agency or shared emotions. On his account, Scheler's grieving parents in fact form a single subject, united by their grief, contrary to the plurality requirement. He argues that such a sense of "us" is constituted by plural pre-reflective self-awareness. Because it is like something for us to have a certain experience, like grieving our child, there is a plural subject to which the experience is given $[11,17]$. Plural pre-reflective self-awareness is not something achieved by the subjects through some form of agreement or declarative act and does not require coordination or shared concerns. Just as singular pre-reflective self-awareness is marked by ownership, perspective, and commitment, so is its plural counterpart. And just like singular pre-reflective selfawareness, its plural form does not need further explanation other than that it is like something for us to have an experience. A pre-reflective plural subject is implied in the shared experience. 
Schmid's account of phenomenological fusion has faced frequent criticism over the years, which I shall not reiterate here in any detail. One convincing example can be found in Zahavi's [18] article "Collective Intentionality and Plural Pre-Reflective Self-Awareness." What matters is that even if Schmid's account were successful in defending its argument for plural pre-reflective selfawareness, it would still not account for how this pre-reflective self-awareness is constituted, claiming instead that it is just as fundamental as singular pre-reflective selfawareness. Moreover, just like in the above cases, the phenomenological fusion Schmid defends appears to be limited to special cases of actual we-experiences where the experiential boundaries between subjects dim to the extent that the experience is that of oneness. It, too, thus falls short in explaining pervasive background feelings of belonging.

In the following, I shall demonstrate that Walther succeeds where other accounts of communal experience and we-intentionality fall short. Schmid [17], in fact, engages with Walther's account in several of his publications. In one article, he claims that it is faced with the problem of infinite regress of mutual empathic experiences and thus fails to account for communal experiences. In another, he suggests that in order to avoid the infinite regress, Walther's notion of unification may be interpreted in a way that maps onto his own notion of plural subjecthood [11]. I disagree with this picture. Walther's account has several advantages over Schmid's: it retains a plurality of subjects that is widely assumed to be necessary for experiences to be properly shared and thus avoids the sharp criticism faced by Schmid's account; it can explain non-actualized communal experiences and is thus a better candidate to get to the core of background feelings of belonging; furthermore, it does not only describe what it is like for an experience to be given to us, rather than you and me, but also how this plural experiencing comes about in the first place, which is through unification.

\section{Walther's Account of Unification}

Gerda Walther's work has appreciated increased attention in recent years and informed research on the constitution of community and shared experiences in contemporary philosophy [19-22]. Her account of unification and her notion of "humans, who also..." have, however, only played a supportive role to date. In the following, I shall take them centre stage. Where other accounts leave off, Walther's work goes one step further in explaining how communal experiencing is constituted. Despite her oftentimes obscure metaphors, the core of her theorizing offers insightful explanations that may aid our understanding of what is at stake in trauma.

Most attention has probably been paid to unification as the last of 4 requirements which Walther identifies as having to be fulfilled for an experience to be communal, that is, to count as a "we"-experience $[19,20]$. The requirements are: (i) common intentionality, i.e. the experience must involve a common intentional object (which may be a common goal, as identified by accounts of joint action, or any other object); (ii) reciprocal awareness of the other having the same experience (as we have seen both in accounts of joint action as well as in the first requirement for shared emotions according to León et al. [12]); (iii) interdependency, that is, the intertwinement of our experiences, which leads to the individual's experience being enriched by the other's experience of it (along similar lines of León et al.'s [12] second requirement for shared emotions); and last but not least (iv) unification or "feeling oneself to be part of a we," the affective requirement which is of special interest here, and which promises to explain what the above-mentioned accounts merely implied [3].

Walther argues that it is through unification that the individual's first-person perspective comes to be intimately linked to another subject's experience. In unification, the individual's intentionality - their experiential relation to the world - integrates the other's point of view and thus comes to be altered by it. Let us look at this in more detail through an example favoured in the phenomenology of communal experiences $[14,19]$. Imagine going to see a movie in the cinema. We can think of 3 different scenarios: in scenario 1, you are alone in the movie theatre; in scenario 2, you are surrounded by other people, all of them strangers; and in scenario 3, you are there with someone, watching the movie together with them. How does your experience differ in these scenarios? The difference between scenarios 1 and 2 is that in the latter, you share the intentional object of your experience, the movie, with a group of strangers. You have a common intentional object; requirement (i) is in place. Casting a look around and catching someone's eye, you can furthermore become reciprocally aware of the other and of having the same experience as them; requirement (ii) is in place. Perhaps your experience of watching the movie becomes enriched by your awareness of the other's experience of the movie: the tension in the movie theatre becomes palpable, the relief spreads through the aisles as one big outbreath. Your experience becomes entwined 
with and enriched by that of the others and thus, requirement (iii) is in place. And yet, when asked "who did you see the movie with?" your reply is unlikely to be "a house full of strangers" - you would, more likely, report that you went to see the movie by yourself.

For a fully fledged we-experience as in scenario 3, something else is required: the feeling of togetherness, of being part of a "we." Linguistically, this experience would be expressed as "we watched the movie together," which, as I mentioned, would not apply in scenario 2.iii. This feeling arises out of unification. In unification, claims Walther, the other's experience becomes integrated into your own. Not only is your experience of the movie somewhat enhanced (as would be the case in 2.iii); it is altered. That is, it does not merely differ in intensity but is qualitatively different. Your first-person perspective on the movie now includes, pre-reflectively, the other's experience too.

Alone, you might have found the romantic scenes between the couple on the screen boring; due to the feeling of watching the flirtations together with someone, however, you find them to incite intrigue and excitement. You might even feel the discomfort of a warm flushing of your cheeks from a shame that you would not have experienced had you seen the same action by yourself, or even in the anonymous company of a movie theatre full of strangers, for that matter. The experience alone, or even surrounded by others but without the special kind of connection that unification is, differs in kind from the experience of watching the movie together. Because you feel unified with the other, their experience alters your own.

Walther [3] describes this state of unification as the other being "in me." I agree with Salice and Uemura that this is to be taken in a somewhat metaphorical sense, which is to say, in terms of intentionality [21, 23]. The other is "in $m e$ " in the sense that they influence the way I experience. Their experience becomes an integral part of my intentionality and vice versa; the experience becomes "ours" and I experience it as such. Note, however, that the "we" arising out of unification does not replace the "I" of the communal experience: the feeling of unification and the altered experience it gives rise to is still experienced by the singular subject, the "I." There is no higher order "we" that replaces the "me" or the "you" of the experience $[3,21]$. Instead, unless brought to awareness through reflection, there is only an implicit "we," in other words, a background feeling of being "us."

Note the affective nature of unification. Walther [3] suggests that the fourth requirement for communal experiences is the affective dimension, a feeling of together- ness, that is, the feeling of having a special kind of connection with the other. It does not involve a cognitive process of thinking about or positing oneself as belonging to another, putting oneself in the other's shoes, predicting their behaviour, having a certain type of knowledge of their experience, or the like [3]. The absence of unification is, therefore, not a cognitive failure, either. I will engage with whether feelings of being understood can be conceptualized as a cognitive achievement in the penultimate section of this article.

\section{Habitual Unification and Walther's Notion of "Humans, Who Also..."}

At this point, one might wonder whether Walther's account faces the same problem as the above-mentioned accounts of we-intentionality. Is unification, as presented above, not also tied to a specific experience of having a common intentional object and reciprocal awareness thereof? Walther replies to this by arguing that, once established, the feeling of unification can become sedimented through habitualisation, in a process much alike that described by Husserl $[24,25]$. What we mean by habitual unification is not that the subject is in constant, actual unification with the other, but rather, that the feeling of unification is constantly in the background of the subject's experience. Past experiences of unification with a person or a group of people become sedimented, they retreat into the background of experience and henceforth colour the individual's present experiences. In other words, the relationship formed through unification becomes established in pre-reflective awareness and continues to shape experiences in a background way. Importantly, in habitual unification, the individual does not have to be involved in any actual we-experience. Whereas a memory of an experience of unification, according to Walther [3], has also retreated to the background of experience and can be recalled, it can never be re-experienced. The habitualised unification, in contrast, can be reactivated any time and lived through once again. It remains in the background of experience, ready to be actualized once more. Let us return to our example. Having previously unified with another person whom, perhaps, I have come to call my friend, and our unification having sedimented over multiple actual we-experiences, amongst them going to the cinema or debating cinematography, even the experience of watching the movie by myself will be altered by my friend's implicit presence. In Walther's words: my friend is habitually "in me" [3]. In this way, my 
experience of the movie takes on a different meaning even when watching it alone: I see it in light of our love for cinema or our hate for one-dimensional female characters.

The subject does not have to be aware of this implicit influence of the other's perspective on their present experience. Whether another actualization is brought about or not, the habitual unification with the other is there, in the background of the subject's awareness, subtly colouring their experiences in a pre-reflective manner. The other continues to "be in" the subject and to influence their experience, without having to be actually present or aware of the same intentional object. By introducing the concept of habitual unification, Walther thus allows for nonactualized experiences of unification, running through the background of the individual's life $[23,26]$.

Of course, most individuals do not form this kind of connection with one person alone. Over one's lifetime, we unify with a multiplicity of other people and form more or less intense habitual bonds with them. Walther takes this to be the (ontological) foundation of community. In phenomenological terms, this broad unification with those in our lives can be understood as the foundation of a feeling of belonging to a shared world. Walther [3] writes:

"How should we think of this deep foundation (of communal life) through habitual unification? As a more or less clear and noticed Mitgehabtheit (co-presence) - even if only in a vague awareness in the background and not in attentive knowledge or presentation - other humans are always "given," "humans, who also..." (This is one of the essential categories for understanding communities. This "also" can be determined in various ways, depending on the kind and intentional foundation of the unification, as humans who "also" value, "also" have such goals, "also" feel, desire, think etc., in the same way as the subject in question... it can also refer to the Grundhaltung (basic attitude) towards the whole of life, the whole cosmos...)." ([3], my translation)

This passage contains reference to 2 essential qualities of feelings of belonging which we have already addressed: the background nature of the feeling of belonging, and the persistence of this feeling over time, even when the feeling is not presently actualized [21]. It furthermore introduces the notion of "humans, who also..." ("Menschen, die auch..." in the German original [3]), the category of other humans who have something in common with me. The ellipsis marks show just how broad this category is to be understood. Any other individual who is experienced as being similar in a significant way, such as having the same thought patterns, experiences, values, or basic attitude towards the whole of life ("Grundhaltung dem ganzen Leben gegenüber" [3]) can be counted as belonging to this group [3]. The experience can be as specific or general as, for

Belonging and Trauma example, also appreciating the scenery, also liking cinnamon rolls, also wanting to leave the house, also hoping for one candidate to be elected but not the other, also believing in karma, etc. Whether it is a specific experience or a goal, value, or world view that the individual has in common with the other, they may be experienced as another "human, who also...." The subject might be only vaguely aware of others who also experience the world in a certain way, as offering certain possibilities, being a safe place, humans who also have a certain basic attitude towards life more generally. I do not need to be explicitly aware of you experiencing the world in a certain way to have a sense that I am not alone in my experience of the world in this way. Due to my habitual unification with you and all the other subjects I have previously connected with, I have a background sense of experiencing the world as others experience it too: as a shared space.

It is not clear, in Walther's writings, whether unification is equivocal with experiencing others as "humans, who also..." or whether one of the concepts ought to be understood as more basic than the other. On the one hand, we can read Walther [3] as suggesting that the subject is vaguely aware of the co-presence of others in the background of their experience because they stand in a relation of unification with them; unification is the foundation of communal experiences. On the other hand, a case can be made for the category of "humans who also..." to be a precondition for unification. Experiencing someone as also having a certain experience, also having the same basic attitude towards the world, etc., prompts the individual to integrate the other into their experience: it enables unification with them in the first place [3]. The above-quoted passage suggests that we are, indeed, to think of habitual unification as the co-presence of "humans, who also...." For Walther [3], "humans who also" is a category that describes a particular form of unification, namely habitual unification [27]. Habitual unification and experiencing others as "humans, who also..." can thus be understood as being equiprimordial $[28,29]$. In other words, habitual unification is neither more basic than the experience of others as "humans who also...," nor the other way around: they are 2 sides of the same coin. Without one, the other cannot exist.

In short, unification alters the phenomenology of the world at large. The world feels different: it is experienced in light of a "we," be that narrow and specific ("me and my best friend") or broad and vague ("me and the rest of humanity"). Being habitual, this feeling becomes integral to one's identity and informs how one experiences oneself as part of a shared world. In the following, I shall direct 
my attention to the trauma testimonies. I will demonstrate how the subject's experience is impacted through traumatizing experiences and why this may lead to a failure of unification and with it an absence of feelings of belonging and of being understood. The central idea I will explore is that experiencing others as "humans who also..." is no longer available to the traumatized individual. Therefore, unification fails and the individual is denied feelings of belonging and of being understood.

\section{The Absence of Background Feelings of Belonging in Trauma}

When considering psychological trauma, researchers often focus their work on post-traumatic stress disorder as the most severe and long lasting of the trauma- and stressor-related disorders [30]. However, (post-)traumatic experiences cover the whole range of the disorders, and more: not all post-traumatic experiences are necessarily pathological and warrant a diagnosis with a disorder. I will therefore not restrict myself to experiences that fall under the DSM's definition of post-traumatic stress disorder but will instead engage with the lived experience of the traumatized individual more broadly speaking. I take "trauma" to encompass the significant alterations to an individual's experience of being in the world following a severely distressing event. While I do not doubt that neurological alterations can be a result of traumatizing experiences, my interest lies with the experiential dimension of trauma.

It appears that a common ailment of trauma survivors is a felt absence of a feeling of belonging and of being understood. While this is not to say that it is a necessary or pervasive feature of post-traumatic experiences, references to feeling like a stranger frequently crop up in trauma testimonies. Consider the following statements, which were collected in an online survey I conducted throughout 2020, as an illustration of this:

\#3. Excluded - not one of us.

\#8. It caused me to feel separate, that I was not the same as other people because we didn't have the same experience.

\#17. No (I don't feel understood by other people). I feel very alone and different to others much of the time.

\#22. I just see things differently but would love to feel connected and part of the way I did up until my 30s. In my 30s, I stopped being able to make deep connections. (sic.)

\#34. Always a feeling of being a stranger to other people.

\#39. I don't think it's possible for anyone to completely understand my experience. I also feel a bit like a stranger.
In the previous section, I have drawn on Walther's work to demonstrate that feelings of belonging may be understood in terms of habitual unification. Furthermore, Walther [3] asks us to think of habitual unification as experiencing others as "humans, who also...." Unification and the experience of others as "humans, who also..." appear to be equiprimordial, that is, one does not occur without the other. I suggest that the latter may be directly impacted through traumatizing experiences, implying the breakdown of the former. References to feeling different, not the same, separate, like a stranger or an alien being can be explained in terms of no longer experiencing others as "humans, who also..." - or, conversely, oneself as a "human, who also..." to others.

"There was a dinner at that conference for all the panelists, many of whom were my old and good friends and close colleagues. Yet as I looked around the ballroom, they all seemed like strange and alien beings to me. Or more accurately, I seemed like a strange and alien being - not of this world" [31].

Sometimes these experiences are explicit, and the individual is - often painfully - aware of them, such as expressed in Stolorow's writing. Other times, these feelings are more elusive and expressed indirectly by reference to feeling like a stranger or by describing the difficulty of establishing close connections with others, like testimony $\# 22$. As we have seen above, the ellipsis in "humans, who also..." can be filled with a variety of attributes that individuals may have in common. (Be reminded of León et al.'s [12] account of shared emotions, who suggest that a balance of similarity and difference is also required for emotional sharing.) Whatever it is, it is relevant for the present enquiry if and only if it prompts unification. In other words, we must ask which attributes filling the ellipsis are relevant to constituting feelings of belonging and are amiss in post-traumatic experience. An alteration to one's basic attitude appears to be a strong candidate for filling the position.

The experience of trauma is so out of the ordinary that the affected individual might lose their fundamental assumptions about the world. Traumatizing experiences are called unimaginable or unintelligible $[1,2]$, overwhelming, unbelievable, and unbearable [32], something that is hard to imagine happening to anyone, least of all yourself. They involve threats to one's life, one's body, one's self, be it war trauma, domestic abuse, adverse childhood experiences, or the sudden and unexpected loss of a loved one. When it does happen to you, it does not make sense. Brison describes her own experience of this in the following words: 
"The fact that I could be walking down a quiet, sunlit country road at one moment and be battling a murderous attacker the next undermined my most fundamental assumptions about the world" [2].

The traumatized individual lives in a world in which such atrocities are possible and can happen to anyone, at any time, including themself. The non-traumatized individual, in contrast, is in a conceptual limbo in which they know atrocities to happen but they do not experience them as being possible to happen to themselves, or anyone close to them, a state Stolorow [33] describes as a "metaphysical illusion":

“(..) through some extraordinary mental gymnastics, while most people take sexual violence for granted, they simultaneously manage to deny that it really exists - or, rather, that it could happen to them. We continue to think that we - and the women we love - are immune to it, provided, that is, that we don't do anything "foolish"' [2].

We like to believe that trauma is something that happens to others and for a reason. The traumatized individual knows better. The 2 attitudes are so fundamentally different that the traumatized individual can no longer perceive themself as being a human who also lives in a safe, shared world. At the same time, they do not perceive others as being other humans who also conceive of the possibility of trauma. The very foundation for establishing close and meaningful bonds is missing: others are no longer experienced as "humans, who also...." Unification is made impossible, and the unification that has formerly been felt shatters with its counterpart. In Herman's [1] words:

"Traumatized people feel utterly abandoned, utterly alone, and cast out of the human and divine systems of care and protection that sustain life. Thereafter, a sense of alienation, of disconnection, pervades every relationship, from the most intimate familial bonds to the most abstract affiliations of community and religion" [1].

Hence, what is at stake in trauma is not only the feeling of being different that might arise out of having had a unique experience that those one is surrounded by did not have. Because the experience is beyond what is generally assumed to be possible, the felt difference is so significant that it results in a pervasive absence of a background feeling of belonging. In other words, because the traumatizing event challenges our fundamental assumptions about the world, and sharing those fundamental assumptions is a key to establishing meaningful connections with others through unification, the traumatized individual is denied the sense of belonging constituted by habitual unification. ${ }^{1}$

\section{Feeling Understood: A Cognitive Achievement}

One may question whether feelings of being understood really are rooted so deeply in a pervasive background feeling of belonging. Another, simpler, way of making sense of feeling understood is taking it to be a cognitive achievement: an individual feels understood when the other can grasp the meaning of what one is saying, be it in words or gestures. They can understand the reasons one gives for feeling the way one does. Conversely, this means that the individual is overcome by a sense of alienation when the other cannot understand the reasons they give for feeling the way they are feeling. It might also appear to the traumatized individual that there simply are no reasons for experiencing either the traumatizing event or the subsequent distress, and that it is thus impossible to make the other understand them. Frequent reports of trauma being "intelligible" or "unspeakable" appear to support this hypothesis. In other words, the individual feels the absence of reasons to convince the other to believe their experience or the inability of the other to understand the reasons they present. Trying to explain the experience of my trauma to you feels like trying to convince you of the flatness of the earth, only that, of course, I am right about the proposition I want you to adopt, resulting in the painful feeling of not being understood. This can be illustrated by the following testimonies from the survey mentioned above:

\#10. Yes. with the death of my son. it is hard to explain the horrific flashbacks I get from seeing him. From the abuse, it's hard to explain the terror the younger me feels when I come in contact with men from th(a)t country (sic).

\#43. I tried to explain it to close friends but they were not able to comprehend it.

While the feeling of being understood might be a question of a cognitive achievement in many cases, I do not think that the sense of alienation reported in trauma tes-

\footnotetext{
1 This absence of feelings of belonging is not unique to testimonies of trauma survivors but can be encountered in narratives of grief and depression, too. In both, individuals are painfully aware of the absence of feelings of belonging that have been replaced by feelings of not being at home in the world. The other is etched into the world, which becomes painfully apparent in their absence in the case of grief. Bereavement thus makes apparent the centrality of the other in shaping one's own experience of everyday life [35]. I would even go so far as to argue that in this sense, grief may be traumatic if the individual is not only robbed of their feeling of belonging to a world with the deceased but of their feeling of belonging to a shared world more generally. Depression testimonies, too, frequently refer to the experience of the impossibility of (re-)establishing bonds with others, the most striking illustration of which is probably Sylvia Plath's well-known metaphor of the bell jar [36].
} 
timonies is best explained in terms of a cognitive failure of this sort. The frequent references to feeling like a stranger suggest that what is at stake is a feeling that goes deeper than just an unsuccessful exchange of propositions, although this might be amongst the effects of a failure of unification. It is a sense of belonging, a background feeling that is woven through the individual's everyday experience of being in a shared world. A simple misunderstanding or failure to convey the reasons for feeling the way I do may be painful and result in feelings of loneliness or abandonment - but alienation appears to be a sense deeper than that, a pervasive feeling that the individual is not necessarily reflectively aware of but that constantly lingers in the background, colouring the individual's experiences without becoming focal. Thus, in many cases of post-traumatic experience, utterances regarding the feeling of not being understood are best explained as an absence of a background feeling of belonging. This is not to say that cognitive, epistemological, or linguistic accounts do not have anything to add to the discourse on trauma and the individual's sense of feeling understood. Quite the opposite, they can further add to understanding the way in which the underlying disturbance of the feeling of belonging expresses itself in everyday interactions.

\section{Further Considerations}

Applying Walther's notion of unification and the experience of others as "humans, who also..." has shed some light on the origin and nature of feelings of alienation post trauma. While the feeling of not being understood frequently referenced in testimonies of trauma survivors may be explained as a cognitive failure, it is, in many cases, better understood as a more pervasive absence of a feeling of belonging. Because others are no longer experienced as similar in a significant way, presumably due to the severe alteration of the traumatized individual's basic attitude, establishing close connections with others through unification is no longer experienced as possible. Formerly established bonds of unification may break down too, leaving the individual feeling "like a stranger." The lack of the pervasive background feeling of belonging that in non-traumatic experience is constituted through habitual unification leaves the individual with a feeling of alienation and of not being understood by those around them. While accounts of we-intentionality can explain specific, actualized communal experiences, be they shared emotions or joint actions, they do not offer an explanation of non-actualized - or back- ground - feelings of belonging or togetherness. Walther's notion of unification and "humans, who also...," on the other hand, can account for background feelings of belonging and thus offers a way of conceptualizing the feelings of alienation experienced by trauma survivors as an absence of this habitual and affective sense of belonging. To conclude, I would like to suggest 3 questions that lend themselves to further consideration.

\section{How Do Traumatized Individuals Relate to Other Victims of Trauma?}

Trauma is often experienced collectively. While going through the same potentially traumatizing event together, such as being part of a combat unit under fire, may form the basis for unification, this is not necessarily the case. How does the collective nature of a trauma impact on the individual experience thereof? And how do victims of collective trauma relate to those they shared the traumatizing experience with? On the other hand, many individually suffered traumas are similar in kind. Again, while this is not necessarily sufficient to establish a connection between survivors, testimonies suggest that in some cases, sharing a similar trauma may contribute to feeling understood:

\#23. Some who have had a similar experience understand but most just pay lip service.

\#35. The people who would understand me are probably the clients I work with who themselves have experienced the kind of abuse I experienced.

\#41. I feel understood by other people who have been through similar experiences.

\#51. I relate to other abuse victims but not to people who have not experienced anything like this.

A detailed phenomenological analysis of the experience of collective or shared trauma and its aftermath promises to yield interesting results.

\section{What Are the Implications for Therapy and \\ Intervention?}

The importance of an empathetic connection with a therapist for the success of the therapeutic intervention is widely acknowledged and well-documented (e.g., [34]). How can the insights about pervasive feelings of belonging and their absence post trauma, which I have described above, contribute to shaping and enhancing the therapeutic relationship?

\section{Is the Loss of Feelings of Belonging Permanent?}

At least a small number of trauma testimonies suggest otherwise. They speak not only of feelings of separation 
and alienation but also of their experiences of connecting and (re-) establishing relationships after the trauma:

\#19. I am not the same person I was before, my behaviour and comprehension of the world is different than it used to be and (most people) are oblivious. However, I have found my spiritual community including my new friends. Many of those people have been through traumatic events and they accept me and are more understanding on all levels.

\#20. To some degree, calling myself an assault victim and engaging in feminist theory around this offered me a sense of belonging.

Actively seeking out recognition of similarities and shared aspects of experience may enable recognizing others once again as "humans who also...," thus making unification possible again. Further research is needed to confirm and refine these preliminary findings and explore potential implications this may have for the recovery process. Furthermore, I suggest that those who are not traumatized themselves can take an active role in enabling unification with trauma survivors. They can support the traumatized by acknowledging that the trauma happened, without downplaying its devastating nature - a strategy Stolorow $[33,37]$ suggests in his recent publications. Traumatizing events do happen. They are part of our shared world, and we are all, inevitably, humans who also live in this world.

\section{Acknowledgments}

I would like to thank Matthew Ratcliffe and Christina van der Feltz-Cornelis for their helpful feedback on earlier versions of this paper. Thanks to Linas Tranas for talking to me about Walther's work, and Oren Bader for inviting me to contribute to this special edition. I am grateful for the very insightful comments by 3 anonymous reviewers.

\section{Conflict of Interest Statement}

The author has no conflicts of interest to declare.

\section{Funding Sources}

L.W. is a doctoral student at the University of York on a teaching scholarship provided by the Department of Philosophy.

\section{Data Availability Statement}

The data that support the findings of this study are not currently openly available but may be shared with third parties for secondary research purposes on request. Enquiries can be directed to the corresponding author.

\section{References}

1 Herman J. Trauma and Recovery. New York: Basic Books; 1992.

2 Brison S. Aftermath: violence and the remaking of a self. New Jersey: Princeton University Press; 2003.

3 Walther G. Zur Ontologie der sozialen Gemeinschaften. In: Jahrbuch für Philosophie und phänomenologische Forschung. 1923. p. $1-158$.

4 Heidegger M. Sein und Zeit. Tübingen: Niemeyer; 2001.

5 Ratcliffe M. Belonging to the world through the feeling body. Philos Psychiatr Psychol. 2009;16(2):195-9.

6 Dolezal L. Shame, vulnerability and belonging: reconsidering Sartre's account of shame. Hum Stud. 2017;40(3):421-38.

7 Zahavi D. Second-person engagement, selfalienation, and group-identification. Topoi. 2019 Mar 25;38(1):251-60

8 Pacherie E. How does it feel to act together? Phenom Cogn Sci. 2014;13(1):25-46.

9 Helm BW. Plural agents. Noûs. 2008;42(1): 17-49.
10 Gilbert M. How we feel: understanding everyday collective emotion ascription. In: von Scheve C, Salmela M, editors. Collective emotions. Oxford: Oxford University Press; 2014. p. 17-31.

11 Schmid HB. Plural self-awareness. Phenom Cogn Sci. 2014;13(1):7-24.

12 León F, Szanto T, Zahavi D. Emotional sharing and the extended mind. Synthese. 2019; 196(12):4847-67.

13 Salmela M, Nagatsu M. How does it really feel to act together? Shared emotions and the phenomenology of we-agency. Phenom Cogn Sci. 2017;16(3):449-70.

14 Zahavi D. You, me, and we: the sharing of emotional experiences. J Conscious Stud. 2015;22(1-2):84-101.

15 Krueger J. The affective "we": self-regulation and shared emotions. In: Szanto T, editor. The Phenomenology of sociality: discovering the "we". London: Routledge; 2015. p. 26377.

16 Scheler M. The nature of sympathy. London: Routledge; 2017.
17 Schmid HB, Wu X. We-experience-with Walther. In: Luft $S$, Hagengruber R, editors. Women phenomenologists on social ontology. Cham, Switzerland: Springer Nature; 2018. p. 105-17.

18 Zahavi D. Collective intentionality and plural pre-reflective self-awareness. J Soc Philos. 2018;49(1):61-75.

19 Osler L. Feeling togetherness online: a phenomenological sketch of online communal experiences. Phenom Cogn Sci. 2020 Jul 21; 19(3):569-88.

20 Szanto T. The phenomenology of shared emotions: reassessing Gerda Walther. In: Luft S, Hagengruber R, editors. Women phenomenologists on social ontology. Cham, Switzerland: Springer Nature; 2020. p. 85-104.

21 Salice A, Uemura G. Social acts and communities: Walther between Husserl and Reinach. In: Calcagno A, editor. Gerda Walther's phenomenology of sociality, psychology, and religion. Cham, Switzerland: Springer Nature; 2018. p. 27-46.

22 Tranas L, Caminada E. Gerda Walther and Hermann Schmalenbach. In: Szanto T, Landweer $\mathrm{H}$, editors. The Routledge handbook of phenomenology of emotion. 1st ed. London: Routledge; 2020. p. 133-43. 
23 Caminada E. Joining the background: habitual sentiments behind we-intentionality. In: Konzelmann Ziv A, Schmid HB, editors. Institutions, emotions, and group agents-contributions to social ontology. Dordrecht, Netherlands: Springer; 2014. p. 195-212.

24 Husserl E. Die Krisis der Europäischen Wissenschaften. HUA VI. Hamburg: Meiner; 1936.

25 Moran D. Edmund Husserl's phenomenology of habituality and habitus. J Br Soc Phenomenol. 2011;42(1):53-77.

26 Calcagno A, editor. Gerda Walther and the possibility of a non-intentional we of community. In: Gerda Walther's phenomenology of sociality, psychology, and religion. Cham, Switzerland: Springer Nature; 2018. p. 57-70.

27 Calcagno A. On the vulnerability of a community: Edith Stein and Gerda Walther. J Br Soc Phenomenol. 2018;49(3):255-66.
28 Sass L. Explanation and description in phenomenological psychopathology. Off J Ital Soc Psychopathol. 2014;20:366-76.

29 Wilde L. Trauma: phenomenological causality and implication. Phenom Cogn Sci. 2021.

30 American Psychiatric Association. Diagnostic and statistical manual of mental disorders (DSM-5). 5th ed. Washington, DC: American Psychiatric Publishing; 2013.

31 Stolorow RD. A phenomenological-contextual, existential, and ethical perspective on emotional trauma. In: Stanghellini G, Broome M, Raballo A, Fernandez AV, Fusar-Poli P, Rosfort R, editors. The Oxford handbook of phenomenological psychopathology. Oxford: Oxford University Press; 2019. p. 895-906.

32 van der Kolk BA. The body keeps the score. New York: Penguin; 2015.
33 Stolorow RD. Trauma and the dismantling of metaphysical illusion. Psychoanal self context; 2021. p. 1-3.

34 Fulford KWM, Davies M, Gipps RGT, Graham G, Sadler JZ, Stanghellini G, et al., editors. Establishing relationships. In: The $\mathrm{Ox}$ ford handbook of philosophy and psychiatry. Oxford: Oxford University Press; 2013. p. 217-20.

35 Ratcliffe M. Grief and phantom limbs: a phenomenological comparison. In: Burns $\mathrm{T}$, Szanto T, Salice A, Doyon M, Dumont A, editors. The new yearbook for phenomenology and phenomenological philosophy. London: Routledge; 2019. Vol. 17; p. 77-96.

36 Plath S. The bell jar. London: Faber \& Faber; 2008.

37 Stolorow RD. Heidegger's Angst and apocalyptic anxiety. Metalepsis. 2021;1(1):120-2. 